\title{
GPS Tracker Application in Manufacturing Companies Based on Android
}

\author{
Muhammad Rifqi \\ Faculty of Computer Study \\ Universitas Mercu Buana \\ Jakarta, 11650 \\ Indonesia
}

\begin{abstract}
GPS technology at this time is commonly used, Because GPS is already a mandatory feature on a Smartphone because it can help in everyday life, such as for example we want to a place that we have never visited and we do not know the route to there, with the GPS we easily go to a place and do not have to worry about getting lost, at this time the GPS can also be used for various needs one of them help the delivery to know the closest distance to the next destination from the current position.By implementing the Haversine Algorithm, it is created on the Android platform using the Kotlin programming language and utilizes the Google Maps API as a Virtual Maps provider. This app connects to the database on the Server and obtains data such as the current position of the car, the delivery destination through the API created and show in the form of JSON FORMAT, thus the user will know the distance of all delivery destinations from the current position so it is expected to make it easier to determine the destination of the next delivery.
\end{abstract}

Keywords: GPS, Haversine, realtime tracker, Location Based, Maps Positioning

\section{INTRODUCTION}

The development of science and technology which is increasingly diera globalization today, it requires us to participate in following these developments, especially for young generation in 4.0 industrial era[1-3]. The development of technology can help in producing an information system quickly, accurately, relevant and on time, where information is needed in various sectors[4]. That will support the development in all fields and can assist in problem solving to produce the right decisions[5]. A mobile-based computerized system is one form of using technology to produce an information system that is needed better and safety[6].

PT. Agung Poly Nugraha is one of companies in the field of manufacturing that focuses on the manufacture of synthetic leather located in Tangerang. All operational activities, such as making raw materials into the leather fibers, conducting new product research, making shipping preparations even to shipping to suppliers are using technologies tracker[7-9]. In the process of shipping to these suppliers often face obstacles, including late delivery trucks to the supplier's place so that the supplier is closed because it is outside the operating hours, often the supplier asks the current truck location to the sales person concerned and the sales person contacted via On Call to the truck driver but sometimes it is very difficult to contact, which is usually the reason the battery runs out, there is no signal, etc[10-12]. In the other hand, there is lost contact and also miss communication between the sender and the recipient so that the item is not sent[13].

Based on the explanation from the background that has been explained before, in general the problems to be solved from this research are:

How to find out the position of the delivery vehicle in real time so that no more items fail shipping?

The research method in this final project includes several things including:

1. Observation Method

Direct observation is carried out when sending to the customer in order to obtain very important information so that it can

be used to analyze the next steps in the construction of the system

2. Library Method

Obtain data by reading and studying books and literature related to the theory and reports of this research.

The objectives to be achieved in this research are:

i. Display a list of the closest destinations from the current position using Haversine Formula 
ii. Make order confirmation feature for drivers

\section{METHODOLOGY}

This study employed the implementation of the Haversine Algorithm, it is created on the Android platform using the Kotlin programming language and utilizes the Google Maps API as a Virtual Maps provider[14-18]. The benefits to be achieved in this study are: The company can monitor the position of the vehicle at this time and Delivery confirmation can be done on the same day no need to wait for the driver to return home. The limitation of the problem in this research is to make shipments that have been ordered in advance.

\section{RESULT AND DISCUSSION}

The implementation after the system has been designed, then the next is the implementation of the system, so that the application can be used according to user needs, in the implementation of this system there are 2 platforms namely the Android and Web platforms[18, 19]

1. Sales Settings: Warehouse Admin

On the Sales menu, the Warehouse Admin can add, change also delete User Sales

To access this menu, the Warehouse Admin enters the Settings menu and selects the Sales submenu

\section{Sales List}

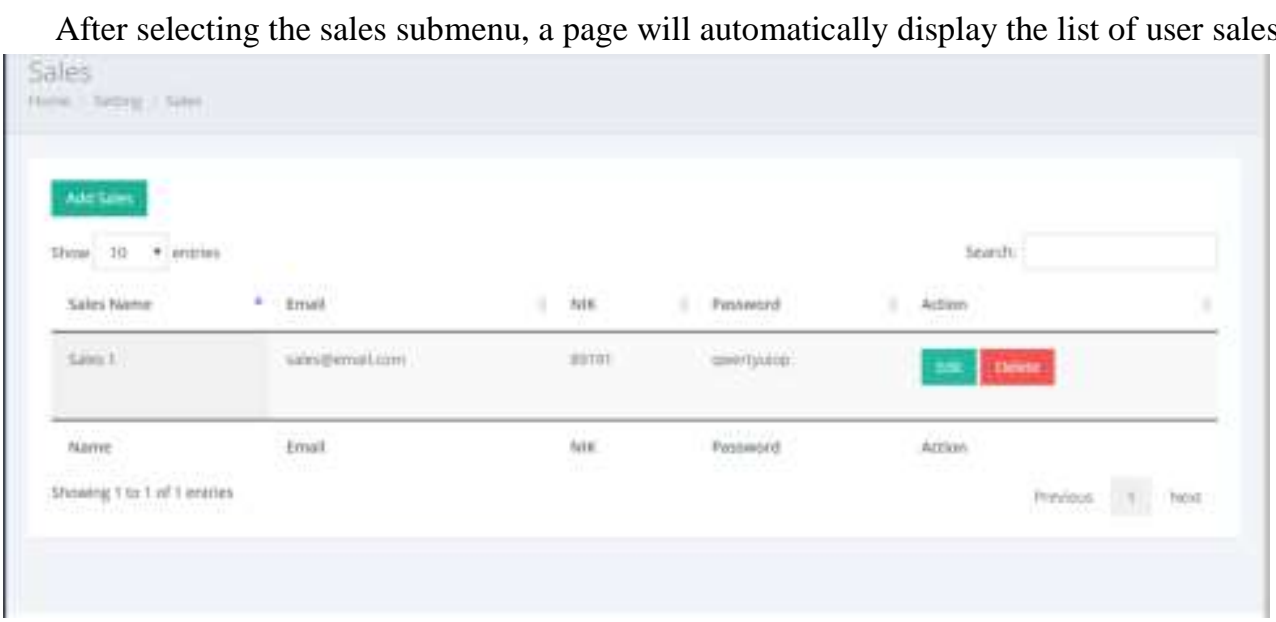

Figure 1. Sales List

\section{Add Sales}

In order for sales to log in and do additional customer activities, before sales must have a user account first

To add a sales account on the Sales Settings menu admin press the Add Sales button, the form will appear as shown below

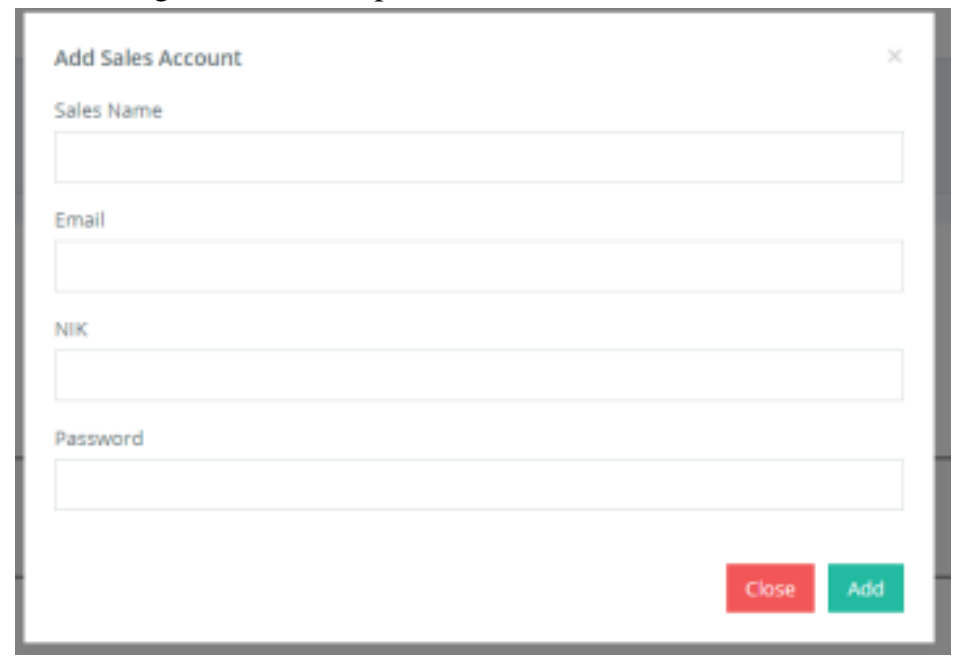

Figure 2. Add Sales

If all fields are filled then click the Add button to add sales after the process of adding a successful sales account then sales can $\log$ in to the system. 


\section{Edit Sales}

If there is an input error of the sales user, the Warehouse Admin can change data such as name, email and password data to make changes to the data by pressing the edit button on the sales who want to change the data, the form will appear as follows

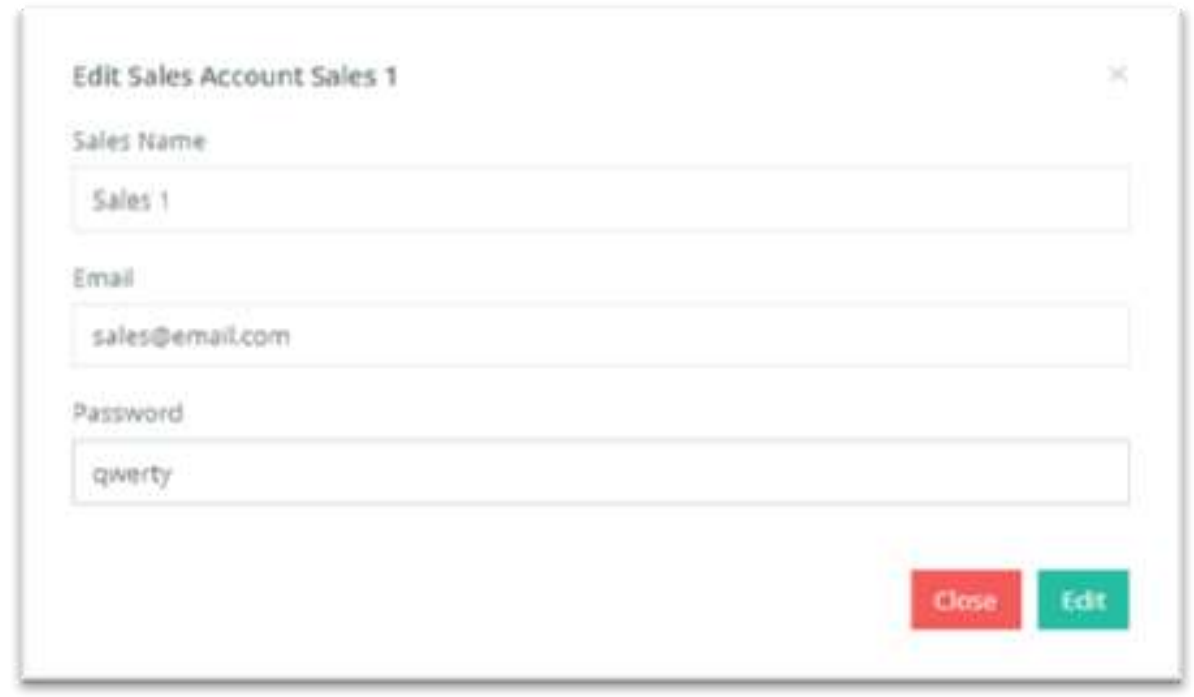

\section{Delete Sales}

Figure 3. Edit Sales

If the sales user is not reused or the sales are not active the Warehouse Admin can delete the sales user by pressing the delete button on the sales that you want to delete, a confirmation will appear if you want to delete the user sales as shown below:

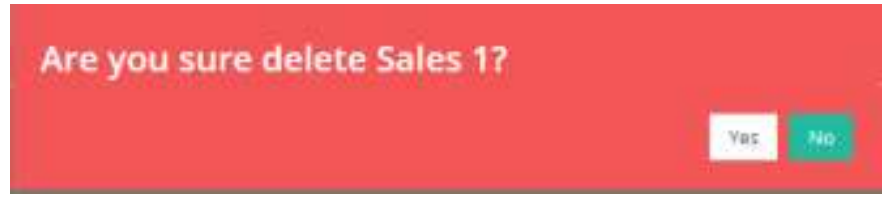

Figure 4. Delete Sales

\section{Vehicle Setting: Warehouse Admin}

To make a shipment, vehicle data is needed to carry the order. The registered vehicle must also be a vehicle that has been installed a GPS device to track the position of the vehicle to access the vehicle list Admin Warehouse selects the Settings menu then the Vehicle submenu, a list will appear as shown below:

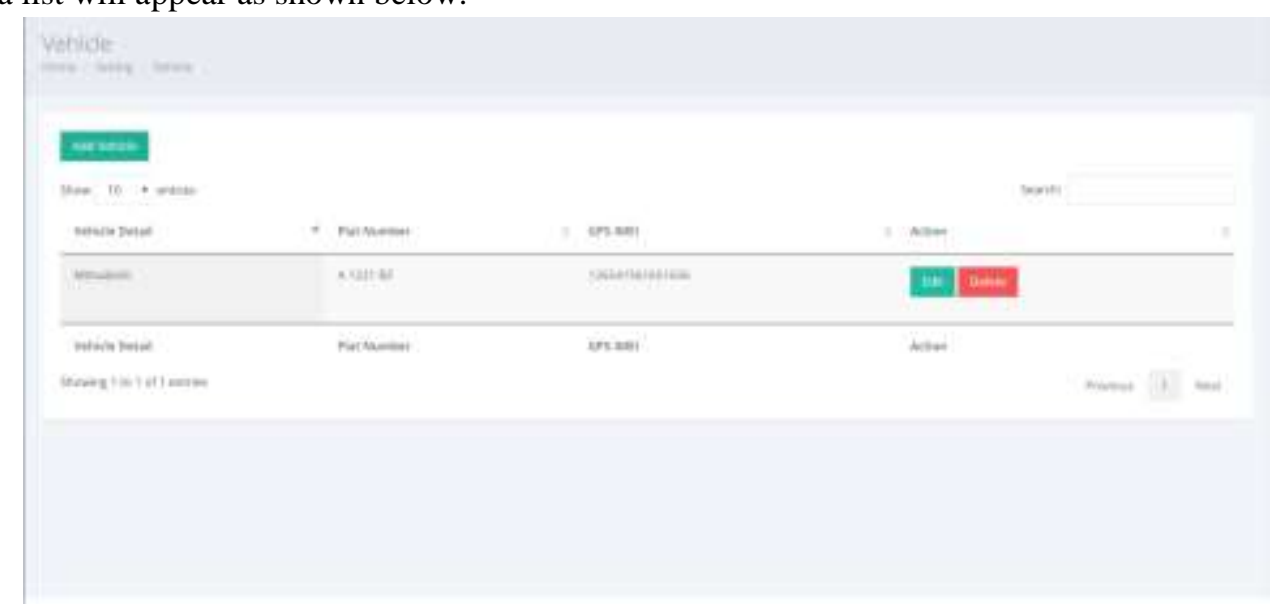

\section{Add Vehicle}

Figure 5. Setting Vehicle

In order for the vehicle to be used when shipping, the Warehouse Admin adds vehicle data by pressing the add vehicle button, then the vehicle will exit the form with the vehicle detail field, vehicle license plate and also the GPS IMEI installed 


\section{Edit Vehicle}

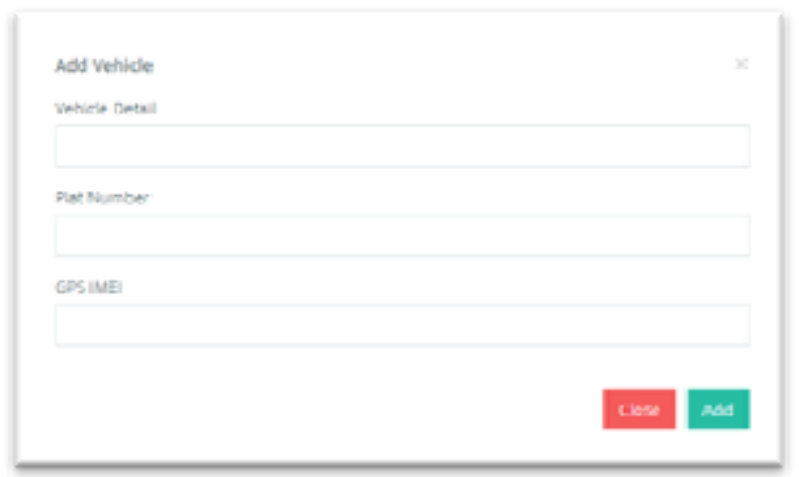

Figure. Add Vehicle

If there are data input errors, the Warehouse Admin can make changes by pressing the edit button on the vehicle to be changed then after making changes, the Warehouse Admin presses the edit button to make changes

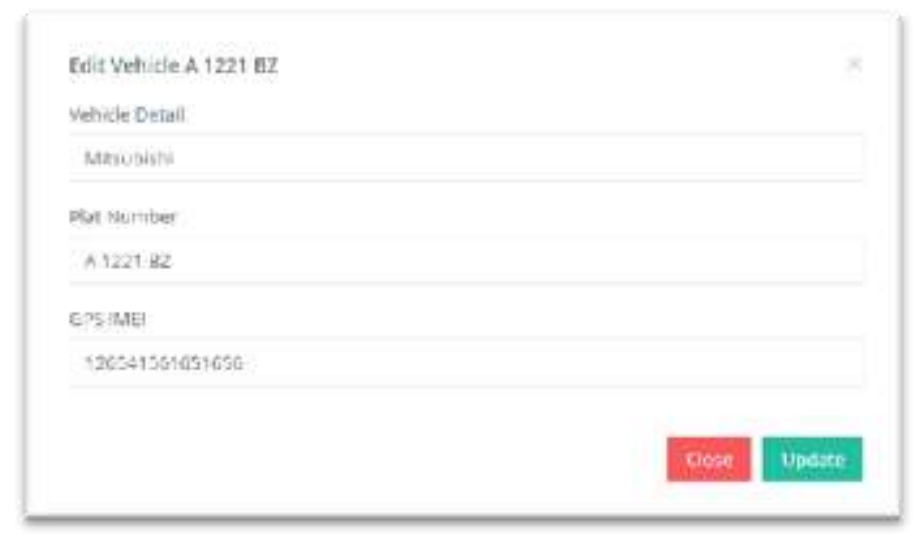

Figure 7. Edit Vehicle

Delete Vehicle

If the vehicle is not used there is also a delete function to delete the vehicle, to delete the Warehouse Admin can press the Action Delete button and a confirmation will appear that the vehicle will be deleted

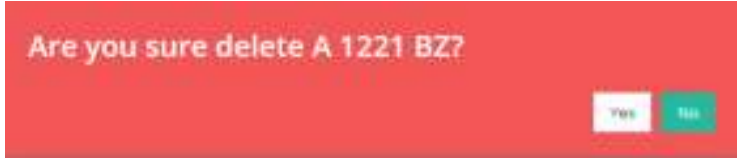

Figure 8.Delete Vehicle

Driver Settings: Warehouse Admin

After the Warehouse Admin adds a vehicle, of course, there must be a driver who will take the vehicle to see the list of drivers that can go to the Settings menu and then to the Driver submenu.

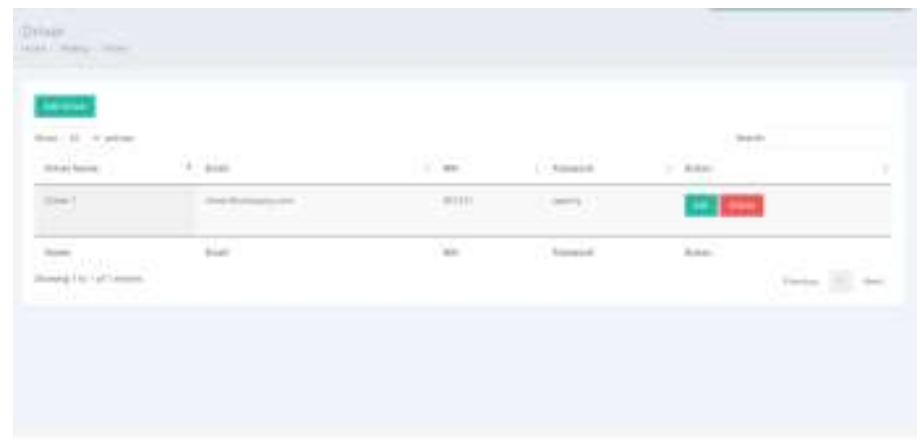

Figure 9. Driver Settings

Add Driver

So that drivers can log into the application, user access is needed, to make user driver access can be done by pressing the add driver button and the form will appear to add the user driver as shown below: 


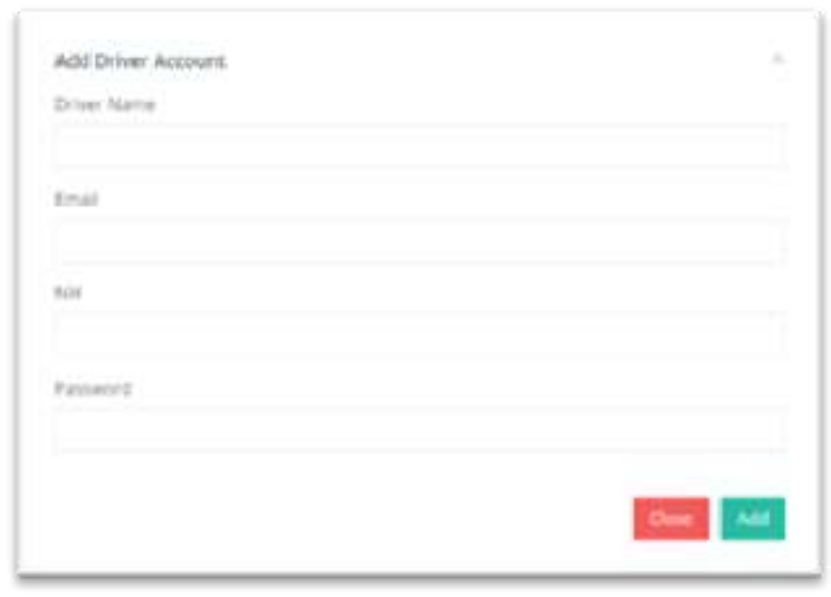

Figure 10. Add Drivers

\section{Edit Driver}

In this menu there is also to change driver data, data that can be changed such as name, email, and Password for the driver login application to change the data driver can press the edit button on the driver who wants to change the data

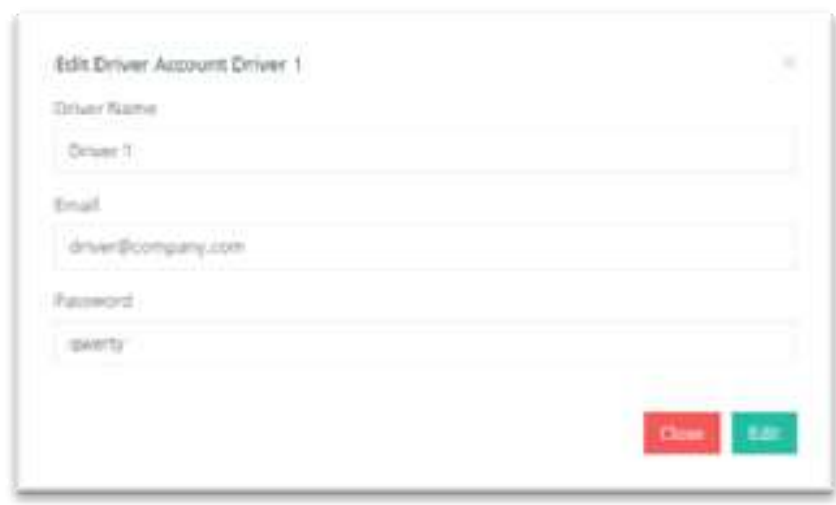

Figure 11. Edit Driver

\section{Delete Driver}

If the driver is no longer active, or there is a data error, the driver can be deleted, by pressing the delete button on the data driver that you want to delete then a confirmation will appear if you want to delete the driver data as shown below:

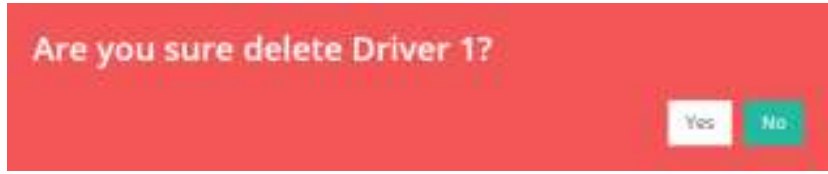

Figure 12. Delete Driver

\section{Realtime Tracker}

To see the current position of the vehicle that can be seen on the menu of Tracker then the realtime sub-menu will display the vehicle registered previously with the current position

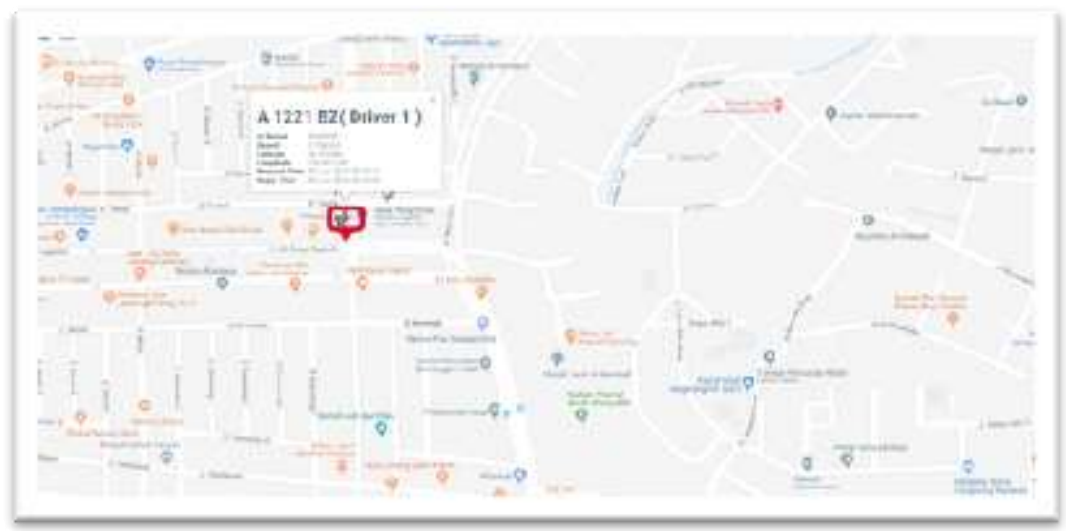

Figure 13. Realtime Driver 


\section{Login Driver}

Before the driver does the activity, the driver is required to log in first, for the user driver can only log in via the application

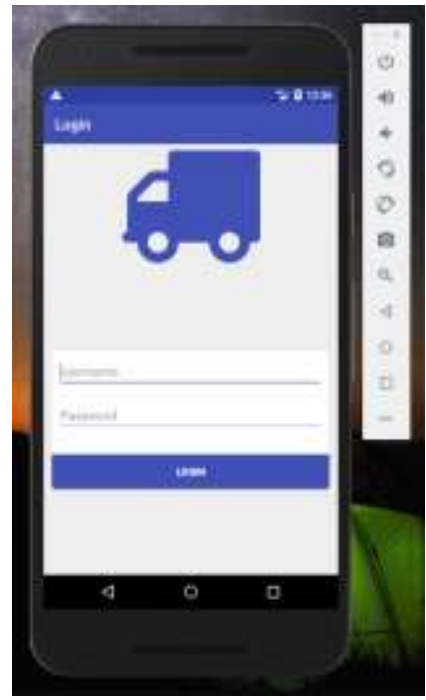

Figure 14. Login Driver

\section{Customer Driver List}

After the User Driver login, the system will direct to the main page, on this main page there is a list of customers that will be visited by the driver

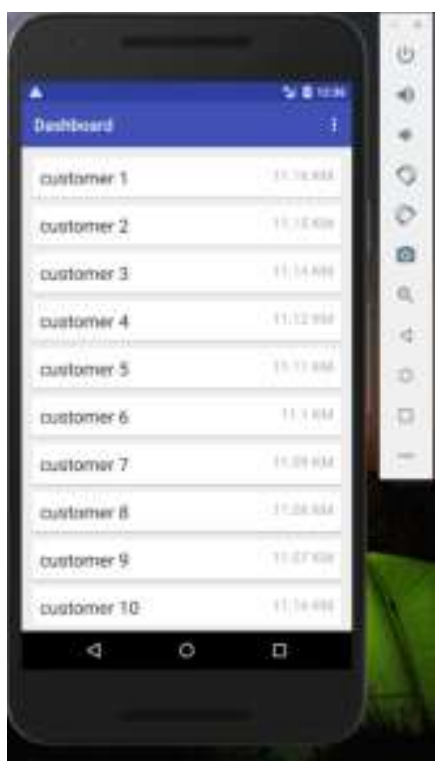

Figure 15. List of Customer Drivers

Driver Delivery Confirmation

If the driver is already at the customer's place, then the next step is the driver confirms the delivery, if there are obstacles such as the store closes then the driver must also cancel the shipment. 


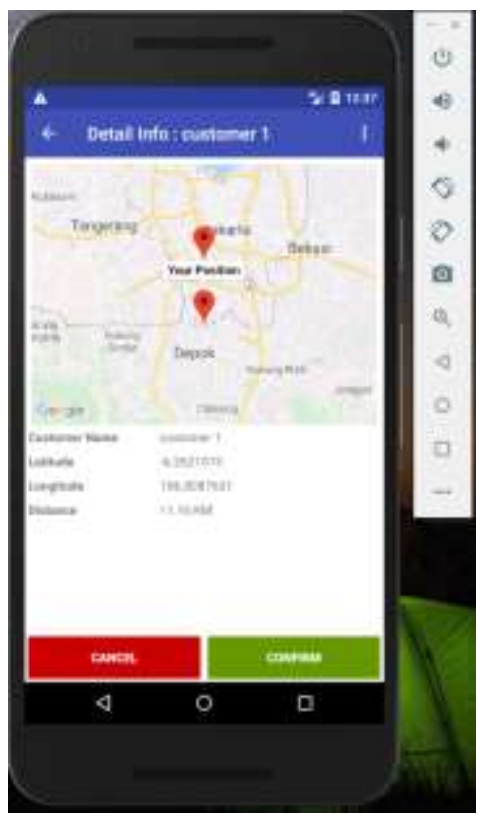

Figure 16. Driver Shipping Confirmation

Database Implementation

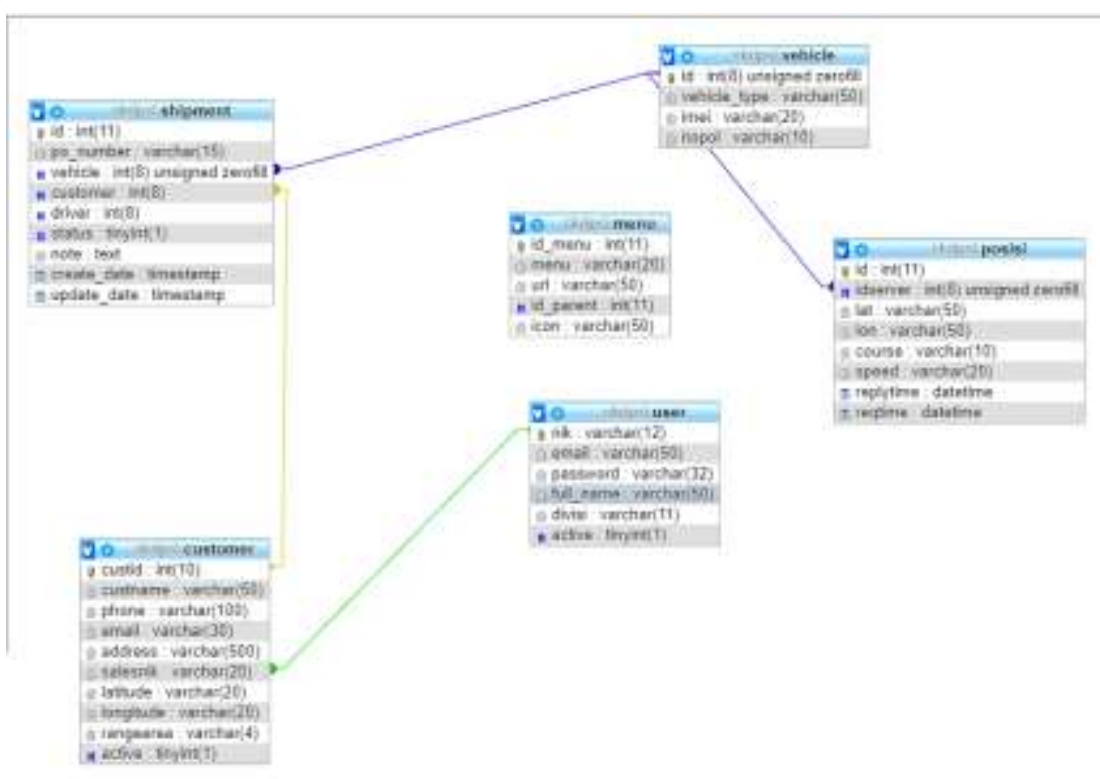

Figure 17. Database Design

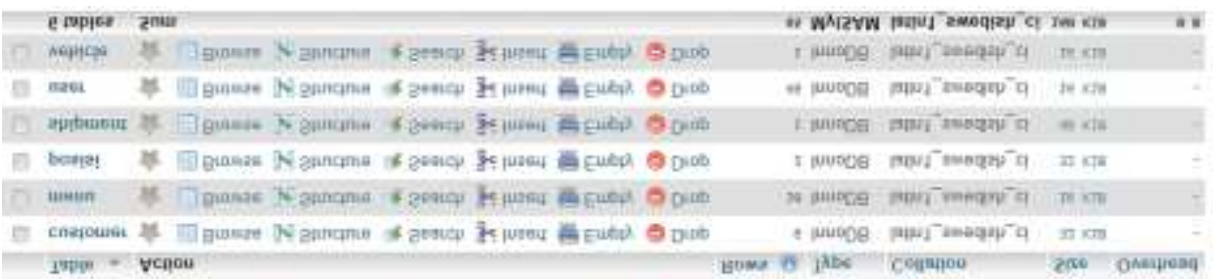

Figure 18. Database List

The current monitoring of the position of the vehicle can only be seen by the company[20]. It is expected that in the future there will also be monitoring the location of the vehicle for the customer so that the customer can know for himself where the vehicle is located. In the current shipping function, shipping is not too detailed, for example, no items are sent, it is hoped that the next developer can add features to the sales order so that the details of the goods sent are displayed.

\section{ACKNOWLEDGMENT}

Best gratitude for Akbar Darmawan, a final year student Universitas Mercu Buana, Jakarta, Indonesia. 


\section{CONCLUSION}

This application internal parties can find out where the current driver position, especially sales can inform the customer that the driver is on his way to his place. The Haversine Formula algorithm is successfully applied to find the closest customer from the current driver's vehicle position, and also the Haversine Formula algorithm is applied to the confirm lock system so that the driver can only confirm delivery if it is already in a certain area. This application also can help drivers to make it easier to determine the closest customer from the position of the current vehicle so that it is expected to be able to streamline the delivery time and also be able to complete the delivery target on that day.

\section{REFERENCES}

[1] T. Izzati, P. Hastuti, I. Gunawan et al., “ An Education Profile Of Indonesian Youth In 2009-2013," Science International, vol. 27, no. 2, pp. 1457-1460, 2015.

[2] D. Ambrose, and R. J. Sternberg, Giftedness and talent in the 21st century: Adapting to the turbulence of globalization: Springer, 2016.

[3] M. B. Steger, Globalization: A very short introduction: Oxford University Press, 2017.

[4] H. W. Beers, Indonesia: Resources and their technological development: University Press of Kentucky, 2015.

[5] M. A. Ramdhani, H. Aulawi, A. Ikhwana et al., "Model of green technology adaptation in small and medium-sized tannery industry," Journal of Engineering and Applied Sciences, vol. 12, no. 4, pp. 954-962, 2017.

[6] T. Izzati, “Analysis of Safe-T-Score by Health and Safety at Work (HSW)," Advanced Science Letters, vol. 22, no. 7, pp. 1827-1830, 2016.

[7] M. Laguna, and J. Marklund, Business process modeling, simulation and design: Chapman and Hall/CRC, 2018.

[8] Y. Fu, J. Ding, H. Wang et al., "Two-objective stochastic flow-shop scheduling with deteriorating and learning effect in Industry 4.0-based manufacturing system," Applied Soft Computing, vol. 68, pp. 847-855, 2018.

[9] B. Hanum, and T. Izzati, "Supplier Selection on Rendement Rate of Patchouli Leaf," International Journal of Engineering \& Technology, vol. 7, no. 3.7, pp. 130-133, 2018.

[10] A. Marotta, L. Studer, G. Marchionni et al., "Possible Impacts of C-ITS on Supply-Chain Logistics System," Transportation research procedia, vol. 30, pp. 332-341, 2018.

[11] Z. Zhang, "Optimization of freight truck driver scheduling based on operation cost model for Less-Than-Truckload (LTL) transportation," 2018.

[12] T. Iseland, E. Johansson, S. Skoog et al., “An exploratory study of long-haul truck drivers' secondary tasks and reasons for performing them," Accident Analysis \& Prevention, vol. 117, pp. 154-163, 2018.

[13] J. Fernie, and L. Sparks, Logistics and retail management: emerging issues and new challenges in the retail supply chain: Kogan page publishers, 2018.

[14] M. Jangid, "Kotlin the unrivalled android programming language lineage," Imperial Journal of Interdisciplinary Research, vol. 3, no. 8, pp. 256-259, 2017.

[15] A. Király, and J. Abonyi, "Redesign of the supply of mobile mechanics based on a novel genetic optimization algorithm using Google Maps API,” Engineering Applications of Artificial Intelligence, vol. 38, pp. 122-130, 2015.

[16] E. A. Obugyei, and N. Raman, Learning Kotlin by building Android Applications: Explore the fundamentals of Kotlin by building real-world Android applications: Packt Publishing Ltd, 2018.

[17] T. Ki, "Enabling API Virtualization on Android for Platform Openness," State University of New York at Buffalo, 2018.

[18] U. Ali, “Android Application for Taxi Management,” 2018.

[19] R. Meier, and I. Lake, Professional Android: John Wiley \& Sons, 2018.

[20] Y. Qiu, M. Ni, L. Wang et al., "Production routing problems with reverse logistics and remanufacturing," Transportation Research Part E: Logistics and Transportation Review, vol. 111, pp. 87-100, 2018. 